\title{
Nieuw onderzoek naar POH-zorg voor kinderen met astma
}

\author{
Sara Bousema
}

Geprotocolleerde zorg kan leiden tot een betere astmacontrole, maar is voor huisartsen (te) tijdrovend. De praktijkondersteuner zou deze taak op zich kunnen nemen. Dat gebeurt nu al bij volwassen astmapatiënten en het is de vraag of dat ook bij kinderen mogelijk is. Rotterdamse onderzoekers bekijken daarom of geprotocolleerde astmazorg door de praktijkondersteuner tot een betere astmacontrole leidt bij kinderen dan de 'usual care' door de huisarts.

Astma is de meest voorkomende chronische ziekte bij kinderen in de huisartsenpraktijk. ${ }^{1}$ De symptomen en exacerbaties kunnen een grote impact hebben op hun kwaliteit van leven en dat van hun ouders. ${ }^{2}$

In Nederland komt zowel over- als onderbehandeling van astma voor. ${ }^{3}$ Onderbehandeling kan resulteren in het onnodig voortbestaan van symptomen, een slechtere astmacontrole en het vaker optreden van exacerbaties. Overbehandeling brengt onnodige kosten met zich mee. In 2015 werden de kosten voor kinderen met luchtwegaandoeningen geschat op 312,9 miljoen euro, waarvan 53,6 miljoen euro per jaar in de eerste lijn. ${ }^{4}$

Eerder onderzoek liet zien dat regelmatige controles en educatie bij volwassenen met astma tot een betere astmacontrole en mogelijk tot kostenreductie leiden. ${ }^{5,6}$ Dit zou ook kunnen gelden voor kinderen met astma. Er bestaan twee richtlijnen die geprotocolleerde astmazorg bij kinderen ondersteunen: de NHG-Standaard en de Zorgstandaard. ${ }^{7,8}$ Deze richtlijnen adviseren gestructureerde controlebezoeken en het opstellen van een individueel zorgplan. De richtlijnen zijn op dit gebied echter slecht geïmplementeerd in de dagelijkse huisartsenpraktijk. Eerder onderzoek in de tweede lijn liet zien dat astmazorg bij kinderen door een verpleegkundige niet onderdoet voor de zorg door een kinderarts wat betreft de astmacontrole. ${ }^{9}$ Om deze redenen onderzoeken we of geprotocolleerde astmazorg door de praktijkondersteuner tot een betere astmacontrole leidt bij kinderen van 6 tot 12 jaar dan de 'usual care' door de huisarts. Het onderzoek loopt tot 2020 .

\section{LITERATUUR}

1. Wijga AH, Beckers MCB. Klachten en kwalen bij kinderen in Nederland. Ned Tijdschr Geneeskd 2011;155:A3464:1-6.

2. Bush A, Fleming L. Diagnosis and management of asthma in children. BMJ 2015;350:h996.

3. Caudri D, Wijga AH, Smit HA, Koppelman GH, Kerkhof M, et al. Asthma symptoms and medication in the PIAMA birth cohort:

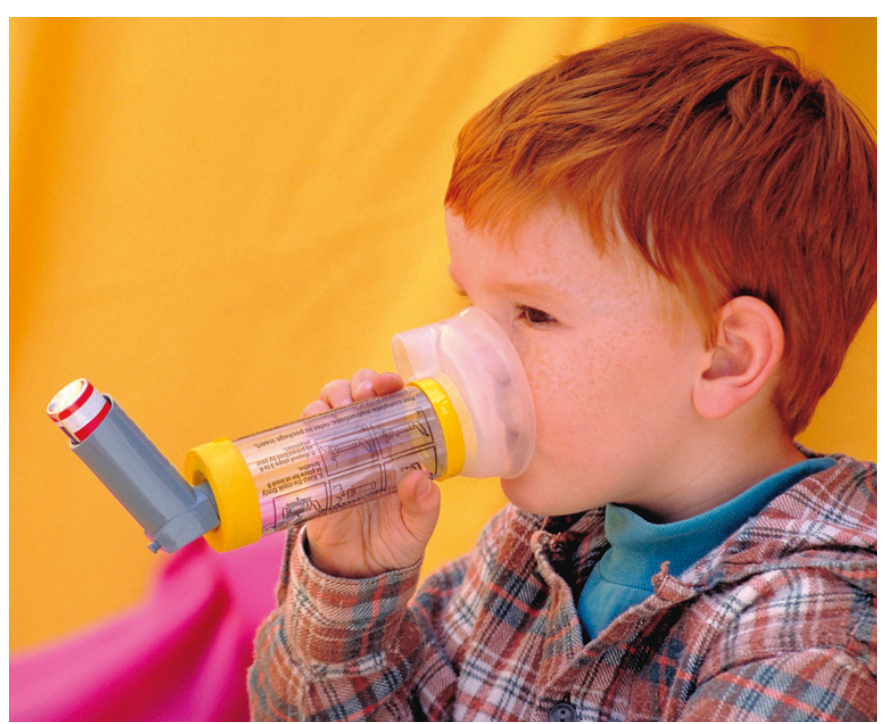

Astma is de meest voorkomende chronische ziekte bij kinderen in de huisartsenpraktijk.

Foto: iStock

evidence for under and overtreatment. Pediatr Allergy Immunol 2011;22:652-9.

4. CBS/RIVM. Databank CBS Statline; kosten van ziekten. Den Haag/Bilthoven: CBS, 2015.

5. Oei SM, Thien FC, Schattner RL, Sulaiman ND, Birch K, Simpson $\mathrm{P}$, et al. Effect of spirometry and medical review on asthma control in patients in general practice: a randomized controlled trial. Respirology 2011;16:803-10.

6. Gibson PG, Powell H, Coughlan J, Wilson AJ, Abramson M, Haywood P, et al. Self-management education and regular practitioner review for adults with asthma. Cochrane Database Syst Rev 2003;1:CD001117.

7. Bindels PJE, Van de Griendt EJ, Grol MH, Van Hensbergen W, Steenkamer TA, Uijen JHJM, et al. NHG-Standaard Astma bij kinderen. Huisarts Wet 2014;57:70-80.

8. Long Alliantie Nederland. Zorgstandaard astma Kinderen \& Jongeren. http://wwwlongalliantienl/files/6513/6752/1347/Zorgstandaard_Astma_Kinderen_en_Jongerenpdf 2012:119.

9. Kuethe MC, Vaessen-Verberne AA, Elbers RG, Van Aalderen WM. Nurse versus physician-led care for the management of asthma. Cochrane Database Syst Rev 2013;2:CD009296.

Bousema S. Nieuw onderzoek naar $\mathrm{POH}$-zorg voor kinderen met astma. Huisarts Wet 2018;61[8]:44. D0I:10.1007/s12445-018-0229-6.

Erasmus MC, afdeling Huisartsgeneeskunde, Rotterdam: S. Bousema, aiotho, s.bousema@erasmusmc.nl.

Belangenverstrengeling: niets gemeld.

Dit is een bijdrage in de rubriek Lopend onderzoek, relevant voor de eerste lijn, geschreven door een promovendus. 